\title{
Effects of Key Properties of Rainfall Series on Hydrologic Design of Sustainable Urban Drainage Systems (SUDS) ${ }^{\dagger}$
}

\author{
Rodrigo Jodra-Lopez *, Alvaro Sordo-Ward, Ivan Gabriel-Martin and Luis Garrote \\ Department of Civil Engineering: Hydraulics, Energy and Environment, Universidad Politécnica de Madrid, \\ 28040 Madrid, Spain; alvaro.sordo.ward@upm.es (A.S.-W.); i.gabriel@upm.es (I.G.-M.); \\ l.garrote@upm.es (L.G.) \\ * Correspondence: rs.jodra@alumnos.upm.es; Tel.: +34-913-336-6672 \\ + Presented at the 3rd International Electronic Conference on Water Sciences, 15-30 November 2018; \\ Available online: https://ecws-3.sciforum.net.
}

Published: 15 November 2018

\begin{abstract}
The aims of this study are to quantify the effects of key properties of rainfall time series on the hydrologic design of sustainable urban drainage systems (SUDS) to test a method for their estimation from daily time series and to quantify their uncertainty. Several typologies of SUDS infrastructures are designed to achieve a target treatment capacity. This target capacity is usually defined according to two methods: treating a percentage of the total volume of rainfall $(50,80,90$, $95,99 \%)$ or treating a percentage of the total number of rainfall events (50, 80, 90, 95, 99\%). We considered the city of Madrid as the case study, compiling 58 years of observed data (10minutetime step) and aggregating to daily time series. We obtained the design parameters from the full resolution dataset and for different storm thresholds $(0,1$ and $2 \mathrm{~mm})$. Second, we determined the design parameters from the aggregated daily time series by applying a temporal stochastic rainfall generator model (RainSimV3). Finally, we estimated the model parameters from daily data and generated 100 series of 58 years at 10-minute time step, then compared the results. Results showed a good agreement compared to the 10-minute time step rainfall series. The different thresholds selected do not affect in a relevant way the calculation by percentage of the total volume; in the case of calculation by events, the threshold can vary the design volume for up to $30 \%$. Further research includes the analysis of different climatelocations.
\end{abstract}

Keywords: SUDS; sustainable drainage systems; hydrologic design; stochastic rainfall generator; stochastic approach

PACS: J0101

\section{Introduction}

Currently, more than half of the world population lives in urban areas and growth is expected [1]. Human activity on the basins induced changes on the hydrological characteristics and higher costs for the construction and maintenance of conventional drainage systems [2,3]. The design and implementation of sustainable urban drainage systems (SUDS) could contribute to mitigating this problem by reducing the runoff volume, peak flow, and outlet contaminants [4-6].

The design of urban drainage systems has traditionally been carried out from historical data or through design storms [7]. However, the small size of the urban watersheds and short response time make it necessary to consider the rainfall series at a sub-hourly time-step [8,9]. From a global perspective, daily time-step rainfall data is the most common available information. Different 
downscaling methodologies have been widely studied for urban applications [10,11], but their application to SUDS design was not fully developed [12-16].

In this study, the temporal disaggregation was analyzed from daily data to 10-minute resolutions based on the Neyman-Scott Rectangular Pulse Method in a single-site and by using the RainSim V.3 model [16]. The aims of this study are to quantify the effects of key properties of rainfall time series on the hydrologic design of sustainable urban drainage systems (SUDS) to test a method for their estimation from daily time series and to quantify their uncertainty.

\section{Materials and Methods}

We analyzed the effect of rainfall design on two types of parameters commonly used to design SUDS: (1) those that treat a percentage of the total volume of accumulated rainfall series $(50,80,90,95,99 \%$, and named as V50, V80, V90, V95, V99), and (2) those that treat a percentage of the total number of rainfall events $(50,80,90,95,99 \%$, and named as N50, N80, N90, N95, N99) during the analyzed rainfall series. The methodology applied was based on the stochastic generation of 10-minute time-step rainfall series (using the RainSimV3 model). First, we obtained the SUDS design parameters from the observed 10-minute rainfall series (58 years) and from aggregated daily rainfall time series. We estimated the parameters of the RainSimV3 model from the observed daily timeseries. Third, we generated 100 series of 58 years at 10-minute time step. Fourth, we validated the Rain Sim V3 model by comparing the intensity-duration-frequency curves (IDF) and rainfall frequency curves obtained from observed and simulated time series. Fifth, we calculated the SUDS parameters. Finally, we compared and analyzed the results.

\subsection{Case Study}

We considered the city of Madrid as the case study. We compiled 58 years of observed data (10minute time step, from 1941 to 1998) from the Madrid Retiro gauge station (id station: 3195). Figure 1 shows the gauge location, centered on the city and located at an altitude of 667 m.a.s.l. (referred to the Alicante sea level). Madrid has a semi-arid climate with an average annual precipitation of $441 \mathrm{~mm}$. The pluviography measurement series has a minimum appreciation of $0.2 \mathrm{~mm}$. By aggregation, the daily data was been obtained.

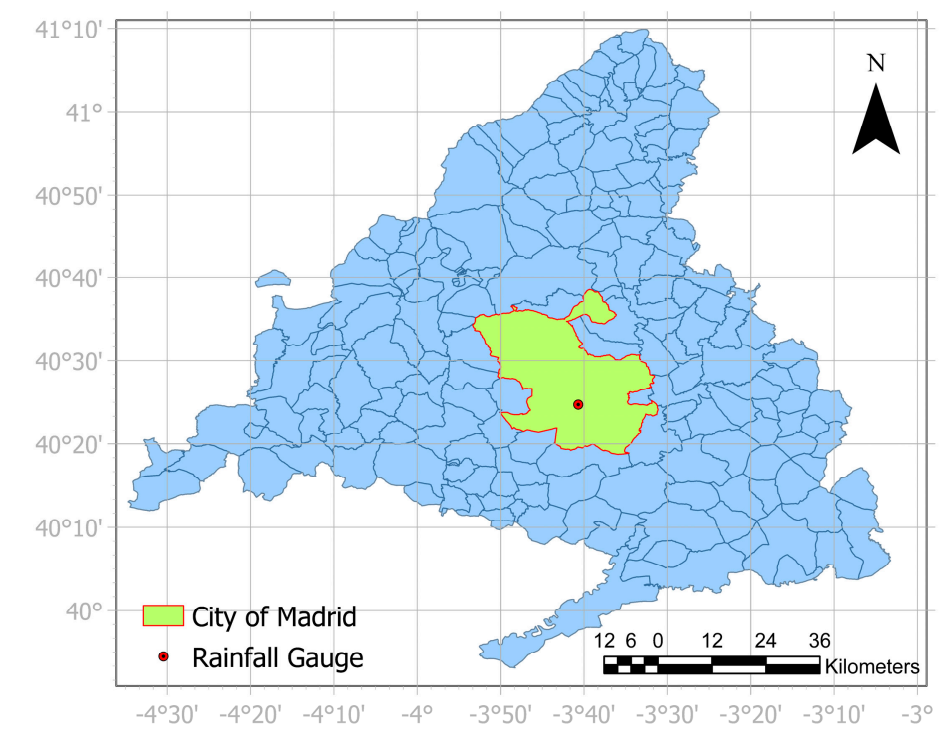

Figure 1. Location of the study case. Red dot indicates the rainfall gauge location.

\subsection{Stochastic Rainfall Generation}

The methodology applied was based on the stochastic generation of 10-minute time-step rainfall series by using the RainSimV3 model. First, we estimated the parameters of the RainSimV3 model 
from the observed daily time series. Second, we generated 100 series of 58 years at 10-minute timestep. Third, we validated the model by comparing (a) the intensity-duration-frequency curves (IDF) obtained by the model and from observed data and from previous studies [17-21], and (b) the rainfall frequency curves obtained from observed and simulated time series and by accounting for different storm durations (10 $\mathrm{min}, 1 \mathrm{~h}$ and $24 \mathrm{~h}$.)

\subsection{Estimation of Design Parameters (SUDS)}

To estimate the SUDS parameters, we first identified the storms from the rainfall series. As usually the available rainfall series are daily time-step, and the minimum inter-storm period considered is a day [22], we assumed independent storms with a minimum inter-storm period of 24 h. We obtained the SUDS design parameters from the observed 10-minute rainfall series (58 years) and from the aggregated daily rainfall time series. We calculated the design parameters for different storm thresholds $(0,1$, and $2 \mathrm{~mm}$ ); that is, by considering all identified storms (threshold $=0$ $\mathrm{mm})$, by considering the storms with a total depth higher than $1 \mathrm{~mm}$ and $2 \mathrm{~mm}$, respectively. For each storm threshold, we generated 100 series of 58 years at 10-minute time step and calculated the SUDS parameters. Finally, we compared and analyzed the results.

\section{Results and Discussion}

\subsection{Stochastic Rainfall Validation}

Table 1 shows the values of the IDF curves obtained from the observed 10-minute time-series, the simulated series, and previous studies. Casas-Castillo et al. [17] used 5-minute rainfall series from1940 to 2012. AEMET [18] obtained the IDF curves by fitting the observed data (10-minute series from1942 to 2002) to a SQRT-ETmax. Distribution function [23]. Finally, results from the application of the national 5.2IC [19] are shown (rainfall values were extracted from the MAXPLU study [20]. Results show that the median values from the stochastic simulations (with parameters adjusted using observed daily data) have a good agreement compared with the results from the 10-minute data, with differences smaller than $10 \%$ for most of the analyzed storm durations and return periods. Moreover, the differences are within the $95 \%$ confidence interval estimated by the stochastic simulations.

Table 1. Comparison of IDF curves according to different sources of data and the methods applied. Dur correspond to the storm duration in minutes and $\operatorname{Tr}$ the return period in years. Values are presented in $\mathrm{mm} / \mathrm{h}$.

\begin{tabular}{|c|c|c|c|c|c|c|c|c|c|c|c|c|c|c|c|c|c|c|c|c|}
\hline \multirow[b]{2}{*}{$\begin{array}{c}\text { Dur/ } \\
\operatorname{Tr}\end{array}$} & \multicolumn{4}{|c|}{ Observed IDF Curve } & \multicolumn{4}{|c|}{ Simulated IDF Curve } & \multicolumn{4}{|c|}{ AEMET (2003) } & \multicolumn{4}{|c|}{$\begin{array}{c}\text { Casas-Castillo et al. } \\
\text { (2016) }\end{array}$} & \multicolumn{4}{|c|}{$\begin{array}{l}\text { 5.2-IC RETIRO } \\
\text { (MAXPLU) }\end{array}$} \\
\hline & 2 & 5 & 10 & 15 & 2 & 5 & 10 & 15 & 2 & 5 & 10 & 15 & 2 & 5 & 10 & 15 & 2 & 5 & 10 & 15 \\
\hline 10 & 35.6 & 49.8 & 59.6 & 65.5 & 37.8 & 55.2 & 67.8 & 74.4 & 34.0 & 52.0 & 65.0 & 71.3 & 38.6 & 55.5 & 68.3 & 75.7 & 35.7 & 47.6 & 55.2 & 59.6 \\
\hline 20 & 23.7 & 37.0 & 45.1 & 49.3 & 27.3 & 40.5 & 50.7 & 56.4 & 26.0 & 38.0 & 48.0 & 52.3 & 25.5 & 36.6 & 45.0 & 49.9 & 25.2 & 33.6 & 38.9 & 42.0 \\
\hline 30 & 19.1 & 27.7 & 37.3 & 38.2 & 20.6 & 30.0 & 37.2 & 41.8 & 20.0 & 30.0 & 38.0 & 41.7 & 19.6 & 28.1 & 34.6 & 38.4 & 20.3 & 27.1 & 31.4 & 33.8 \\
\hline 60 & 11.6 & 17.7 & 20.3 & 22.0 & 12.6 & 17.8 & 21.5 & 23.9 & 12.5 & 18.0 & 22.2 & 24.1 & 12.2 & 17.5 & 21.6 & 23.9 & 13.8 & 18.3 & 21.3 & 22.9 \\
\hline 120 & 7.5 & 10.7 & 12.8 & 16.1 & 7.1 & 10.0 & 12.2 & 13.5 & 7.9 & 10.9 & 13.0 & 14.0 & 7.5 & 10.8 & 13.2 & 14.7 & 9.1 & 12.1 & 14.0 & 15.1 \\
\hline 360 & 3.8 & 4.8 & 5.3 & 6.0 & 3.3 & 4.4 & 5.1 & 5.5 & 3.8 & 5.0 & 5.9 & 6.3 & 3.4 & 4.9 & 6.0 & 6.7 & 4.4 & 5.8 & 6.8 & 7.3 \\
\hline 720 & 2.3 & 3.0 & 3.3 & 3.5 & 2.2 & 2.8 & 3.3 & 3.6 & 2.4 & 3.1 & 3.6 & 3. & 2.1 & 3.0 & 3.6 & 4.0 & 2.7 & 3.5 & 4.1 & 4.4 \\
\hline 1440 & 1.4 & 1.8 & 2.2 & 2.3 & 1.4 & 1.8 & 2.1 & 2.3 & 1.5 & 1.9 & 2.2 & & 1.2 & 1.8 & 2.2 & 2.4 & 1.6 & 2.1 & 2.4 & 2.6 \\
\hline 10 & \multirow{4}{*}{\multicolumn{4}{|c|}{ Comparative Value[\%] }} & 6.1 & 10.9 & 13.7 & 13.5 & -4.6 & 4.5 & 9.0 & 8.8 & 8.3 & 11.5 & 14.5 & 15.5 & 0.2 & -4.4 & -7.4 & -9.1 \\
\hline 20 & & & & & 15.3 & 9.4 & 12.3 & 14.3 & 9.8 & 2.7 & 6.3 & 6.0 & 7.7 & -1.1 & -0.3 & 1.1 & 6.4 & -9.2 & -13.8 & -14.9 \\
\hline 30 & & & & & 8.0 & 8.4 & -0.4 & 9.3 & 4.9 & 8.4 & 1.7 & 9.0 & 2.8 & 1.6 & -7.4 & 0.4 & 6.5 & -2.0 & -15.9 & -11.6 \\
\hline 60 & & & & & 8.9 & 0.6 & 5.9 & 8.4 & 8.0 & 1.8 & 9.3 & 9.3 & 5.4 & -1.1 & 6.4 & 8.4 & 19.3 & 3.5 & 4.9 & 3.9 \\
\hline 120 & \multirow{3}{*}{\multicolumn{4}{|c|}{$100 \cdot \frac{(\text { Comp.. }- \text { Observed })}{\text { Observed }}$}} & -4.9 & -6.5 & -4.4 & -16.7 & 5.8 & 2.0 & 1.9 & -13.3 & 0.5 & 1.0 & 3.4 & -8.9 & 21.9 & 13.2 & 9.7 & -6.4 \\
\hline 360 & & & & & -12.6 & -9.7 & -3.1 & -8.8 & -0.3 & 3.3 & 12.1 & 4.5 & -10.8 & 1.3 & 14.0 & 11.1 & 15.4 & 19.9 & 29.2 & 21.0 \\
\hline 720 & & & & & -4.8 & -5.6 & -0.6 & 2.3 & 4.7 & 3.3 & 7.6 & 8.0 & -8.4 & 0.0 & 7.6 & 13.6 & 17.8 & 16.6 & 22.5 & 25.0 \\
\hline 1440 & & & & & 0.0 & 0.0 & -4.2 & 0.0 & 7.1 & 5.6 & 0.6 & 0.0 & -14.3 & 0.0 & 2.2 & 4.3 & 14.3 & 16.7 & 9.7 & 13.0 \\
\hline
\end{tabular}


Figure 2 shows the rainfall frequency curves (RFC) corresponding to rainfall durations of 10 min, $1 \mathrm{~h}$ and $24 \mathrm{~h}$ respectively. Simulated RFC curves for $1 \mathrm{~h}$ and $24 \mathrm{~h}$ show an excellent agreement compared with their correspondent observed RFC curves (calculated from 10-minute time series). It should be noted that the simulated RFC curves were generated with parameters estimated from daily data. Thus, the proposed stochastic procedure has a good predictive capacity for extreme value estimation.

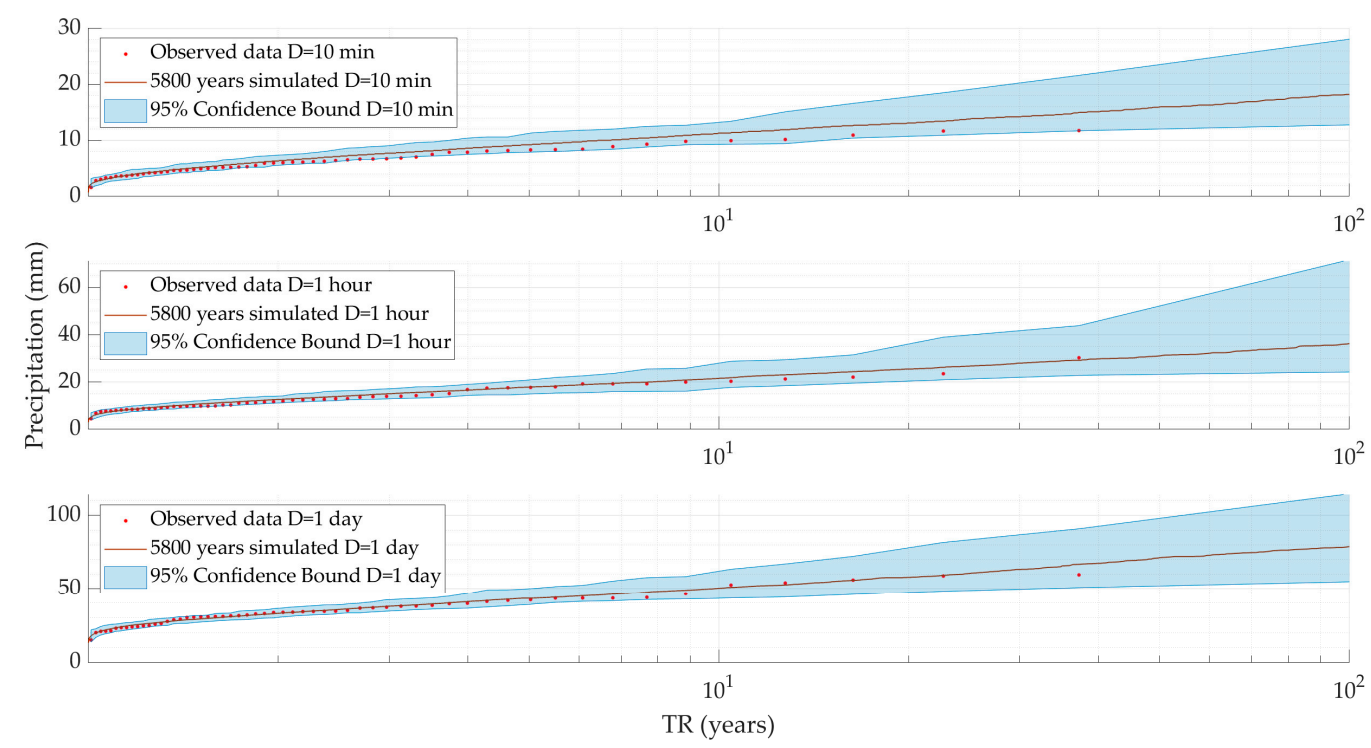

Figure 2. Comparison of the estimated rainfall frequency curves corresponding to 10-minute storm duration (D, red dots), $1 \mathrm{~h}$ and 1 day, their corresponding stochastic simulation (red line), and 95\% confidence bound (cyan area).

\subsection{Design Parameters Analysis (SUDS)}

\subsubsection{Parameters Based on Rainfall Volume}

Figure 3 and Table 2 shows, for the different storm thresholds considered, the values and uncertainty of the V50, V80, V80, V90, V90, V95, and V99 derived from the 100 analyzed series. In addition, values obtained from the observed 10-minute and daily time series are also plotted. Although results show better performance of the stochastic series assuming a threshold value of 2 $\mathrm{mm}$ compared with $1 \mathrm{~mm}$ and considering all events, the SUDS design parameters, for this case study, did not present high sensitivity. For V50, V80, and V90, better results were obtained for the stochastic approach than for daily data. Thus, starting from observed daily data, the stochastic approach could obtain similar SUDS design values than using observed daily data, but also estimated a 10-minute time-step series, very useful for SUDS design. For example, for a better estimation of storm characteristics as temporal distribution of storms, time among events, and maximum and mean rainfall intensities, among others. Finally, results from observed 10-minute time step are within the $95 \%$ confidence bound of the stochastic simulation. 

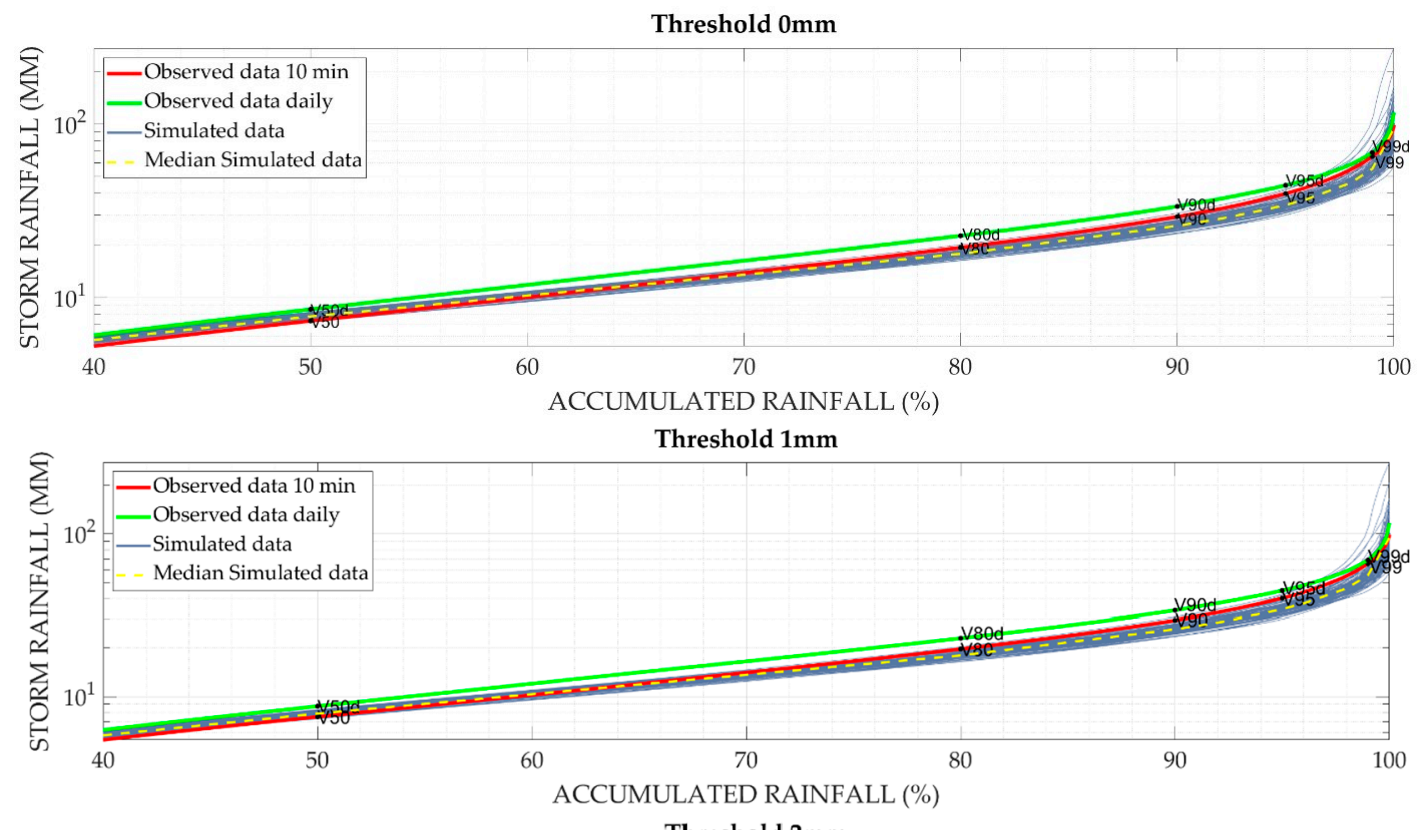

Threshold 2mm

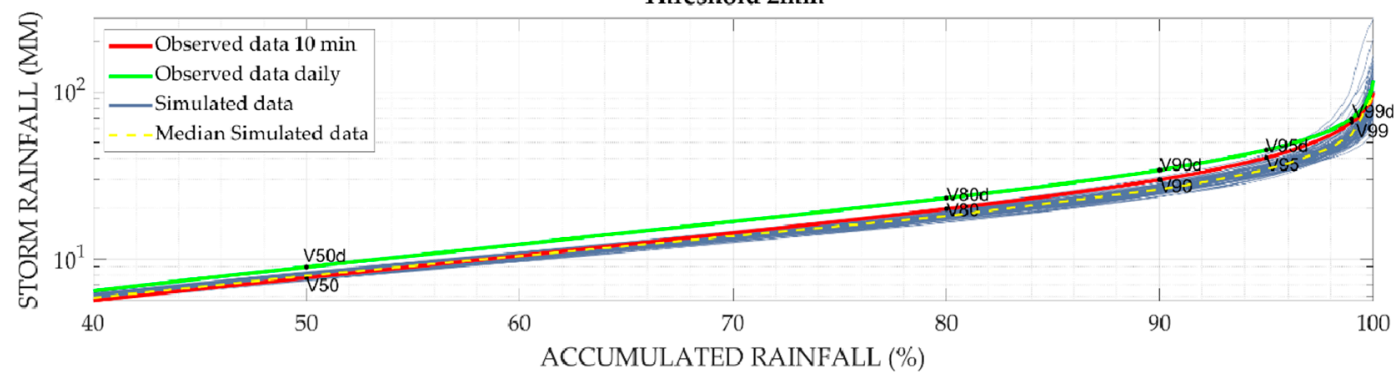

Figure 3. Comparison of the SUDS parameters based on rainfall event volumes. Red line represents the event rainfall volume value that ensure a treatment of the $50,80,90,95$, and $99 \%$ of the accumulated rainfall depth within the analyzed period (58 years) at 10-minute time step. Green line corresponds to daily time step, blue lines correspond to the stochastic simulations at 10-minute timestep, and yellow dotted line represent the median values of the stochastic simulation.

Table 2. Comparison of the SUDS design values (V50, V80, V90, V95 and V99) in mm. by using the10minute observed data, daily observed data and stochastic generated data, and by considering different storm thresholds $(0,1$ and $2 \mathrm{~mm})$.

\begin{tabular}{|c|c|c|c|c|c|c|c|}
\hline & \multirow{2}{*}{ Observed $10 \mathrm{~min}$} & \multirow{2}{*}{ Observed Daily } & \multicolumn{2}{|c|}{ Simulated } & \multirow{2}{*}{$\begin{array}{c}\text { Error Daily } \\
\text { Median }\end{array}$} & \multicolumn{2}{|c|}{ Error Simulated } \\
\hline & & & Min & Max & & $\%$ & $\%$ \\
\hline \multicolumn{8}{|c|}{ Threshold $0 \mathrm{~mm}$} \\
\hline V50 & 7.35 & 8.57 & 7.23 & 8.25 & 7.8 & $17 \%$ & $6 \%$ \\
\hline V80 & 19.53 & 22.89 & 16.4 & 20.3 & 18 & $17 \%$ & $-8 \%$ \\
\hline V90 & 29.39 & 33.64 & 23.4 & 30.8 & 26.15 & $14 \%$ & $-11 \%$ \\
\hline V95 & 40.17 & 44.81 & 30 & 42.9 & 34.5 & $12 \%$ & $-14 \%$ \\
\hline V99 & 65.38 & 69.94 & 44.7 & 112.5 & 57.25 & $7 \%$ & $-12 \%$ \\
\hline \multicolumn{8}{|c|}{ Threshold $1 \mathrm{~mm}$} \\
\hline V50 & 7.49 & 8.72 & 7.29 & 8.32 & 7.85 & $16 \%$ & $5 \%$ \\
\hline V80 & 19.78 & 22.96 & 16.5 & 20.4 & 18 & $16 \%$ & $-9 \%$ \\
\hline V90 & 29.6 & 33.93 & 23.5 & 30.9 & 26.2 & $15 \%$ & $-11 \%$ \\
\hline V95 & 40.15 & 44.8 & 30.4 & 42.9 & 34.6 & $12 \%$ & $-14 \%$ \\
\hline V99 & 67.55 & 69.93 & 44.7 & 112.5 & 57.25 & $4 \%$ & $-15 \%$ \\
\hline \multicolumn{8}{|c|}{ Threshold $2 \mathrm{~mm}$} \\
\hline V50 & 7.75 & 8.95 & 7.41 & 8.41 & 7.96 & $15 \%$ & $3 \%$ \\
\hline
\end{tabular}




\begin{tabular}{lccccccc}
\hline V80 & 20 & 23.3 & 16.6 & 20.5 & 18.2 & $17 \%$ & $-9 \%$ \\
V90 & 29.9 & 34.21 & 23.6 & 31.2 & 26.25 & $14 \%$ & $-12 \%$ \\
V95 & 40.82 & 45 & 30.4 & 42.9 & 34.65 & $10 \%$ & $-15 \%$ \\
V99 & 67.55 & 69.94 & 44.7 & 112.5 & 57.25 & $4 \%$ & $-15 \%$ \\
\hline
\end{tabular}

\subsubsection{Design Parameters Based on Number of Events}

Figure 4 and Table 3 show, for the different storm thresholds considered, the values and uncertainty of the N50, N80, N90, N95, and N99 derived from the 100 analyzed series. In addition, values obtained from the observed 10-minute and daily time series are also presented. Resultsshow a good performance of the simulated N80, N90, N95, and N99 by considering a storm threshold of 2 $\mathrm{mm}$. For design parameters based on the number of identified events, both the storm threshold considered and the criteria adopted to identify independent storms affect results significantly. For N80, N90, N95, and N99, better results were obtained for the stochastic approach than for daily data (storm threshold $=2 \mathrm{~mm}$ ).

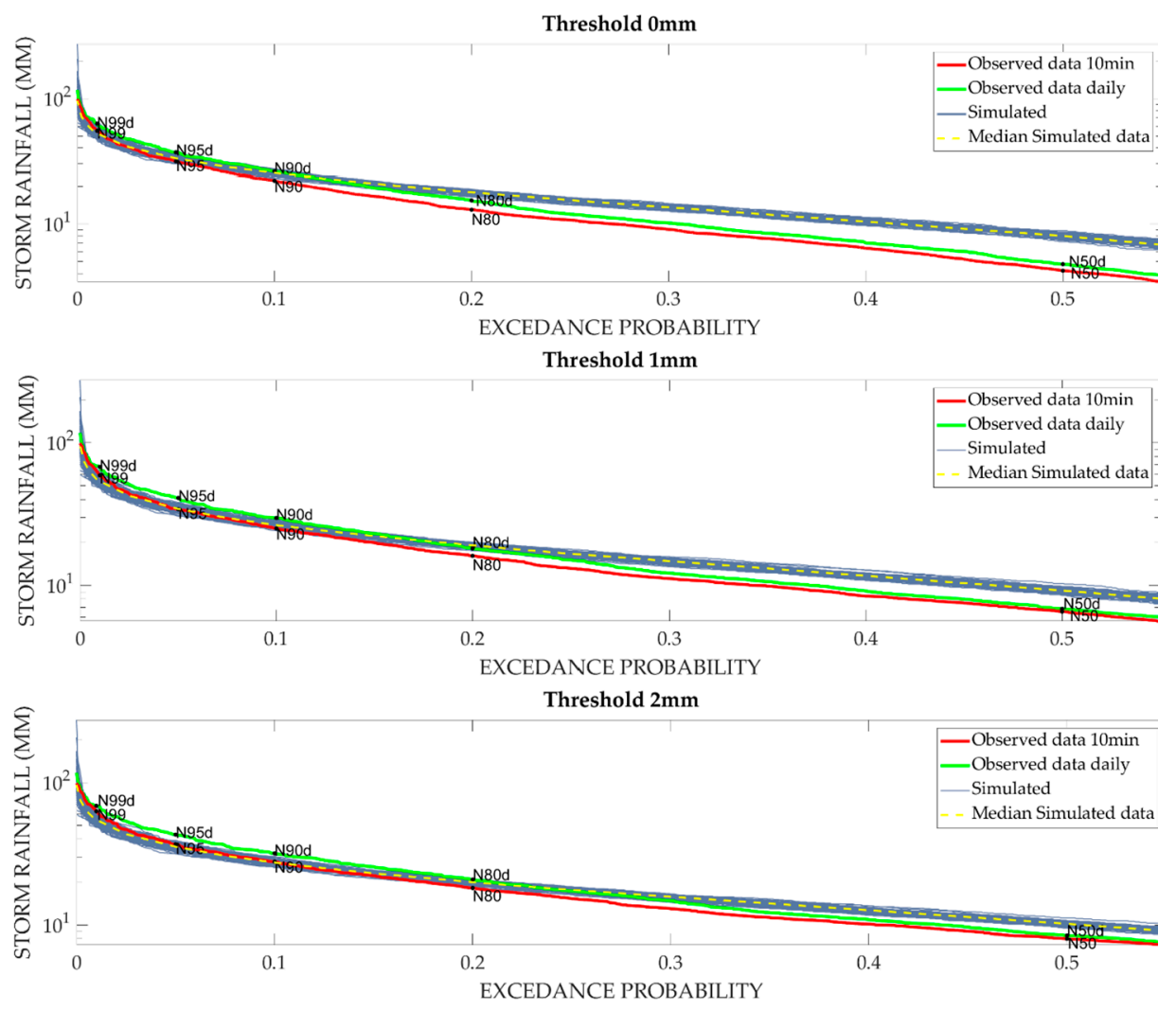

Figure 4. Comparison of the SUDS parameters based on the number of rainfall events. Red line represents the event rainfall volume value that ensure a treatment of the 50, 80, 90, 95 and $99 \%$ of the total storm events within the analyzed period (58 years) at 10-minute time step. Green line corresponds to daily time step, blue lines correspond to the stochastic simulations at 10-minute timestep and yellow dotted line represent the median values of the stochastic simulation.

Table 3. Comparison of the SUDS design values (N50, N80, N90, N95 and N99) in mm. by using the10minute observed data, daily observed data and stochastic generated data, and by considering different storm thresholds $(0,1$ and $2 \mathrm{~mm})$.

\begin{tabular}{|c|c|c|c|c|c|c|c|}
\hline & \multirow{2}{*}{ Observed $10 \mathrm{~min}$} & \multirow{2}{*}{$\begin{array}{c}\text { Observed } \\
\text { Daily }\end{array}$} & \multicolumn{3}{|c|}{ Simulated } & \multirow{2}{*}{\multicolumn{2}{|c|}{-Error Daily \% Error Simulated \% }} \\
\hline & & & Min & Max & Median & & \\
\hline \multicolumn{8}{|c|}{ Threshold $0 \mathrm{~mm}$} \\
\hline N50 & 4.2 & 4.75 & 7.2 & 8.8 & 8 & $13 \%$ & $90 \%$ \\
\hline N80 & 13.03 & 15.42 & 16.4 & 19 & 17.9 & $18 \%$ & $37 \%$ \\
\hline
\end{tabular}




\begin{tabular}{lccccccc} 
N90 & 22.15 & 26.1 & 23.13 & 27.32 & 25.35 & $18 \%$ & $14 \%$ \\
N95 & 31.29 & 37 & 29.9 & 36.48 & 33.11 & $18 \%$ & $6 \%$ \\
N99 & 55.02 & 62.83 & 46.19 & 63.19 & 52.4 & $14 \%$ & $-5 \%$ \\
\hline \multicolumn{7}{c}{ Threshold 1 mm } \\
N50 & 6.54 & 6.85 & 8.5 & 10.3 & 9.2 & $5 \%$ & $41 \%$ \\
N80 & 16.09 & 18.15 & 17.5 & 20.02 & 19.07 & $13 \%$ & $19 \%$ \\
N90 & 25.07 & 29.63 & 24.13 & 28.88 & 26.4 & $18 \%$ & $5 \%$ \\
N95 & 34.12 & 40.9 & 30.55 & 38.07 & 34.3 & $20 \%$ & $1 \%$ \\
N99 & 59.015 & 67.67 & 47.91 & 66.029 & 53.6 & $15 \%$ & $-9 \%$ \\
\hline \multicolumn{7}{c}{ Threshold 2 mm } \\
N50 & 8 & 8.42 & 9.5 & 11.2 & 10.2 & $5 \%$ & $28 \%$ \\
N80 & 18.18 & 20.84 & 18.5 & 21 & 20 & $15 \%$ & $10 \%$ \\
N90 & 27.82 & 31.77 & 25.3 & 30.3 & 27.45 & $14 \%$ & $-1 \%$ \\
N95 & 36.8 & 43.05 & 31.5 & 39.2 & 35.45 & $17 \%$ & $-4 \%$ \\
N99 & 62.84 & 68.6 & 48.3 & 69.95 & 57.76 & $9 \%$ & $-8 \%$ \\
\hline
\end{tabular}

\section{Conclusions}

The use of a stochastic approach for the generation of 10-minute time step rainfall series from daily observed data showed a good agreement compared to the 10-minute time step rainfall series. The proposed approach allows the estimation of very useful rainfall characteristics for SUDS design as the temporal distribution of storms, time among events, maximum, and mean storm rainfall intensities, among others. For the case study analyzed, the stochastic approach generated 10-minute rainfall series with IDF curves, and rainfall frequency curves similar to observed data. Parameters to design SUDS based on the number of storms identified have more dependence on the criteria, adopted to define independent storms or the minimum value of rainfall to consider a storm. However, the parameters to design SUDS based on the volume of the storm events are not sensible to the mentioned criteria. This approach allows us to quantify the associated uncertainty of the values adopted to the design of SUDS. It should be noted that we applied this methodology to one location. This might limit the generalization of the results obtained. Further research will be focused on the application of this approach on locations with different climate characteristics.

Author Contributions: R.J.-L. led the numerical calculations, led the analysis and discussion of results and participated in the paper writing. A.S.-W. led the design of the proposed methodology, participated in the analysis and discussion of results and led the paper writing. I.G.-M. participated in the numerical calculations, the analysis and discussion of results and participated in the paper writing. L.G. contributed to the general idea of the research, participated in the analysis and discussion of the results.

Funding: This research received no external funding

Acknowledgments: We acknowledge the financial support of the "Programa propio: ayudas a proyectos de I + Dde investigadores posdoctorales" of the Universidad Politécnica de Madrid and the AEMET support for providing the rainfall data. The authors also acknowledge the funds from the Universidad Politécnica de Madrid in the framework of their Program "Ayudas para contratos predoctorales para la realización del doctorado ensus escuelas, facultad, centro e institutos de I + D + $\mathrm{i}^{\prime \prime}$ and the funds from Carlos Gonzalez Cruz Foundation.

Conflicts of Interest: The authors declare no conflict of interest. The founding sponsors had no role in the design of the study; in the collection, analyses, or interpretation of data; in the writing of the manuscript, and in the decision to publish the results.

\section{References}

1. United Nations. World Urbanization Prospects: The 2011 Revision; United Nations Department of Economic and Social Affairs (Population Division): New York, NY, USA, 2011.

2. Hair, L.; Clements, J.; Pratt, J. Insights on the Economics of Green Infrastructure: A Case Study Approach. In Proceedings of the Water Environment Federatio. WEFTEC 2014: Session 310 through Session 317, New Orleans, LA, USA, 27 September-1 October 2014; pp. 5556-5585, doi:10.2175/193864714815938869. 
3. Sordo-Ward, A.; Bianucci, P.; Garrote, L.; Granados, A. How safe is hydrologic infrastructure design? Analysis of factors affecting extreme flood estimation. J. Hydrol. Eng. 2014, 19, 04014028, doi:10.1061/(ASCE)HE.1943-5584.0000981.

4. Arora, A.S.; Reddy, A.S. Multivariate analysis for assessing the quality of stormwater from different urban surfaces of the Patiala City, Punjab (India). Urban Water J. 2013, 10, 422-433, doi:10.1080/1573062X.2012.739629.

5. Hatt, B.E.; Fletcher, T.D.; Walsh, C.J.; Taylor, S.L. The influence of urban density and drainage infrastructure on the concentrations and loads of pollutants in small streams. Environ. Manag. 2004, 34, 112124, doi:10.1007/s00267-004-0221-8.

6. Woods-Ballard, B.; Wilson, S.; Udale-Clarke, H.; Illman, S.; Scott, T.; Ashley, R.; Kellagher, R. The SUDS Manual, C753; Ciria: London, UK, 2015.

7. Mikkelsen, P.S.; Madsen, H.K.; Arnbjerg-Nielsen, K.; Jørgensen, H.K.; Rosbjerg, D.; Harremoës, P. A rationale for using local and regional point rainfall data for design and analysis of urban storm drainage systems. Water Sci. Technol. 1998, 37, 7-14, doi:10.1016/S0273-1223(98)00310-2.

8. Bennett, N.D.; Croke, B.F.W.; Guariso, G.; Guillaume, J.H.A.; Hamilton, S.H.; Jakeman, A.J.; Marsili-Libelli, S.; Newham, L.T.H.; Norton, J.P.; Perrin, C.; et al. Characterising performance of environmental models. Environ. Model. Softw. 2013, 40, 1-20, doi:10.1016/j.envsoft.2012.09.011.

9. Cowpertwait, P.S. A spatial-temporal point process model of rainfall for the Thames catchment, UK. J. Hydrol. 2006, 330, 586-595, doi:10.1016/j.jhydrol.2006.04.043.

10. Rodriguez-iturbe, I.; Depower, B.F.; Valdes, J.B. Rectangular pulses point process models for rainfall: Analysis of empirical data. J. Geophys. Res. Atmos. 1987, 92, 9645-9656, doi:10.1029/JD092iD08p09645.

11. Entekhabi, D.; Rodriguez-Iturbe, I.; Eagleson, P.S. Probabilistic representation of the temporal rainfall process by a modified Neyman-Scott rectangular pulses model-Parameter-estimation and validation. Water Resour. Res. 1989, 25, 295-302, doi:10.1029/WR025i002p00295.

12. Paschalis, A.; Fatichi, S.; Molnar, P.; Rimkus, S.; Burlando, P. On the effects of small scale space-time variability of rainfall on basin flood response. J. Hydrol. 2014, 514, 313-327, doi:10.1016/j.jhydrol.2014.04.014.

13. Kaczmarska, J.; Isham, V.; Onof, C. Point process models for fine-resolution rainfall. Hydrol. Sci. J. 2014, 59, 1972-1991, doi:10.1080/02626667.2014.925558.

14. Khaliq, M.N.; Cunnane, C. Modelling point rainfall occurrences with the Modified Bartlett-Lewis Rectangular Pulses Model. J. Hydrol. 1996, 180, 109-138, doi:10.1016/0022-1694(95)02894-3.

15. Burton, A.; Kilsby, C.G.; Fowler, H.J.; Cowpertwait, P.S.P.; O'Connell, P.E. RainSim: A spatial-temporal stochastic rainfall modelling system. Environ. Model. Softw. 2008, 23, 1356-1369, doi:10.1016/j.envsoft.2008.04.003.

16. Cowpertwait, P.S.P. A spatial-temporal point process model with a continuous distribution of storm types. Water Resour. Res. 2010, 46, W12507, doi:10.1029/2010WR009728.

17. Casas-Castillo, M.C.; Rodriguez-Sola, R.; Navarro, X.; Russo, B.; Lastra, A.; Gonzalez, P.; Redano, A. On the consideration of scaling properties of extreme rainfall in Madrid (Spain) for developing a generalized intensity-duration-frequency equation and assessing probable maximum precipitation estimates. Theor. Appl. Climatol. 2018, 131, 573-580, doi:10.1007/s00704-016-1998-0.

18. INM (AEMET). Curvas de Intensidad-Duración-Frecuencia. [CD, Recurso Electrónico]; Ministerio de Medio Ambiente: Madrid, Spain, 2003.

19. Ministerio de Fomento. Instrucción de Carreteras 5.2-IC Drenaje Superficial; Dirección General de Carreteras; Ministerio de Fomento: Madrid, Spain, 2016. (In Spanish)

20. Ministerio de Fomento. Máximas Lluvias Diarias en la España Peninsular; Dirección General de Carreteras; Ministerio de Fomento: Madrid, Spain, 1999. (In Spanish)

21. 21. Sordo-Ward, A.; Bianucci, P.; Garrote, L.; Granados, A. The influence of the annual number of storms on the derivation of the flood frequency curve through event-based simulation. Water 2016, 8, 335, doi:10.3390/w8080335. 
22. Stormwater Management Manual. City of Portland. 2016. Available online: https://www.portlandoregon.gov/ bes/64040 (accessed on 15 August 2018).

23. Etoh, T.; Murota, A.; Nakanishi, M. SQRT-Exponential Type Distribution of Maximum. In Proceedings of the International Symposium on Flood Frequency and Risk Analyses, Louisiana State University, Baton Rouge, LA, USA, 14-17 May 1986; Shing, V.P., Ed.; Reidel Publishing Company: Boston, MA, USA, 1987; pp. 253-264.

(C) 2018 by the authors. Licensee MDPI, Basel, Switzerland. This article is an open access article distributed under the terms and conditions of the Creative Commons Attribution (CC BY) license (http://creativecommons.org/licenses/by/4.0/). 